\title{
A BAD AIR DAY IN HOUSTON
}

by R. M. Banta, C. J. Senff, J. Nielsen-Gammon, L. S. Darby, T. B. Ryerson, R. J. Alvarez, S. P. Sandberg, E. J. Williams, and M. Trainer

A case study from the Texas Air Quality Study 2000 field campaign in Houston illustrates the role of small-scale meteorological processes in producing high-pollution events.

A ir pollution continues to be a critical problem in major urban centers around the globe. To address this in the United States, Congress has mandated the National Weather Service of the National Oceanic and Atmospheric Administration (NOAA) to issue air-quality forecasts for major metropolitan regions beginning in 2005. Accurate forecasts for several hours, a day, or two days or more in advance would allow susceptible individuals to adjust their lives, and industry to make informed, responsive, and responsible decisions about emission cutbacks, work schedules, and other factors they may be able to control. Forecasting the occurrence of high-pollution events is a difficult problem, however, because it requires simultaneous knowledge of the local meteorology and air chemistry.

AFFiliations: Banta, SenfF, Darby, Alvarez, and SandberGNOAA/Environmental Technology Laboratory, Boulder, Colorado; SENFF AND WILLIAMS-Cooperative Institute for Research in the Environmental Sciences, University of Colorado, Boulder, Colorado; Ryerson, Williams, AND Trainer-NOAA/Aeronomy Laboratory, Boulder, Colorado; NIELSEN-GAMMON-Department of Atmospheric Sciences, Texas A\&M University, College Station, Texas CORRESPONDING AUTHOR: Robert M. Banta, NOAA/ET2, 325 Broadway, Boulder, CO 80305

E-mail: robert.banta@noaa.gov

DOI:10.II75/BAMS-86-5-657

In final form 31 January 2005

(C)2005 American Meteorological Society
The potential for exceeding air pollution standards is ultimately determined by emissions. Except for systematic differences, such as weekday versus weekend commuter traffic, emissions often do not vary much from day to day, yet only some days have high pollutant concentrations. These pollution concentrations are determined by a complex interplay among three factors: the emissions to the atmosphere, chemical reactions, and meteorology, which determines dispersion. In the absence of accidental releases or spills, whether high-pollution concentrations form on a given day is controlled mostly by meteorological processes, which either dilute pollutant emissions or allow them to accumulate, and can also affect other key processes, such as chemical reaction rates.

Because these processes and interactions are very complex, issuers of air-quality forecasts will rely on numerical weather prediction (NWP) model output for guidance in formulating their forecasts. The reliability of the forecasts thus will depend on the accuracy of the models. The current generation of models, including those described recently by McHenry et al. (2004) and Vaughan et al. (2004) in addition to the Weather Research and Forecasting Atmospheric Chemistry model (WRF-Chem) that is now under development, show much skill in predicting pollution episodes and events. As pointed out by Dabberdt et al. (2004), however, today's models still need improvement in a number of areas, such as representation of many atmospheric boundary layer 
processes, to produce the level of accuracy in quantitative predictions that will be required for reliable air-quality forecasts.

Assessment of current model capabilities, identification of where improvements are needed, and implementation and testing of these model improvements will require comprehensive field-measurement campaigns, in which both meteorology and chemistry are measured simultaneously and in detail. To date, few datasets of sufficiently high resolution and high quality are available to help understand key meteorological and chemical processes, develop forecast procedures, and address NWP modeling issues, including those just described.

A dataset that has detailed meteorology and chemistry measurements to address these meteorological and modeling issues has been obtained during the Texas Air Quality Study in August and September 2000 (TexAQS2000). The six-week campaign featured in-situ and remote sensing instrumentation, both surface based and on airborne platforms. Here we use analyses of the comprehensive data from a day during this campaign to show how much detailed measurements can provide insight into processes that models need to get right to make accurate airquality forecasts.

The challenge in accurately predicting which days are going to be high-pollution days is to forecast reliably whether future meteorological processes will allow the accumulation of pollutants over an area or will disperse them. If pollutants are predicted to accumulate, then it must further be determined where high pollutant concentrations will be and how high these concentrations will become.

Here we illustrate many aspects of this forecasting challenge by investigating the role of meteorological processes in the buildup of pollutants to produce a 1-h ozone $\left(\mathrm{O}_{3}\right)$ standard exceedance [hourly average $>120$ parts per billion (ppb)] in Houston, Texas, using a case study from TexAQS2000. Ozone is a photochemical pollutant that has demonstrated harmful effects when it comes in contact with plants and animals (National Academy of Sciences 1991), and high concentrations of ground-level $\mathrm{O}_{3}$ have been correlated with many human health problems (e.g., Bell et al. 2004). Insight into the meteorological processes causing such exceedances is made possible by the deployment of state-of-the-art airborne and land-based instrumentation during TexAQS2000. The present study exploits the unique measurement capabilities of the airborne, downward-looking, $\mathrm{O}_{3}$-profiling differential-absorption lidar (DIAL) system (Alvarez et al. 1998; Senff et al. 1998; Banta et al. 1998), flown by the NOAA/Environmental Technology Laboratory in a DC-3 aircraft during the study. This lidar maps out the distribution of ozone and aerosol backscatter in a $2 \mathrm{D}$ vertical curtain along the flight track, and thus is capable of showing the 3D distribution of these pollutants by flying patterns over a region. These capabilities were used in concert with other instrumentation to characterize meteorological contributions to air pollution and pollutant distribution near Houston in a manner not otherwise possible.

Several recently completed studies from this campaign (Kleinman et al. 2002; Wert et al. 2003; Ryerson et al. 2003) have already established the role of routine emissions of several highly reactive hydrocarbon species in setting the potential for high- $\mathrm{O}_{3}$ concentrations. Among urban areas in North America, these industrial emissions are unique to the Houston metropolitan area. Hourly averaged $\mathrm{O}_{3}$ concentrations of close to $200 \mathrm{ppb}$ were measured at surface sites on several occasions during this project, and instantaneous concentrations of $\sim 250 \mathrm{ppb}$ were also measured. Such high concentrations were not a daily occurrence, despite relatively constant emissions from day to day (Ryerson et al. 2003); on many days, $\mathrm{O}_{3}$ concentrations did not exceed $100 \mathrm{ppb}$. In this paper we describe the meteorological conditions that led to the highest $\mathrm{O}_{3}$ concentrations observed during TexAQS2000.

BACKGROUND. Air pollution in the Houston area is a product of strong emissions coupled with specialized meteorological conditions. Significant emissions are from Houston urban activity, from power plants, and, to the east and southeast of the city, from many refineries and petrochemical industrial plants along the Ship Channel and the western shore of Galveston Bay (Fig. 1a). Summertime meteorological conditions involve interactions between sea-breeze circulations, which are driven by the temperature contrast between the warm land and the relatively cooler offshore waters, and the larger-scale geostrophic or gradient flows. Along the western shore of Galveston Bay between LaPorte and Texas City (Fig. 1a), the daytime sea-breeze progression often starts with an easterly Galveston Bay breeze generated by the local land-water contrast, then $1-2 \mathrm{~h}$ later a larger-scale southerly to southeasterly Gulf of Mexico breeze prevails.

Sea-breeze circulations driven by the thermal contrast at the coast take two forms. First, the diurnal cycle of the coastal temperature contrast produces a steady 24 -h rotation of the wind vector about the 
larger-scale gradient wind; this rotation is a manifestation in low-level wind observations of an apparent inertia-gravity wave response near the coast. If the gradient wind is light to moderate, the wind perturbation associated with the diurnal sea-breeze cycle (i.e., the inertia-gravity wave) can temporarily counteract the gradient wind to produce a few hours of stagnant wind conditions. When the gradient flow is offshore (from north or northwest), this stagnant period occurs during the afternoon hours.

\section{NUMERICAL WEATHER PREDICTION MODELS AND}

MEASUREMENTS IN AIR OUALITY

NWP models simulate physical and chemical processes and their interactions in the atmosphere, making them important tools for combining all these processes into a quantitative prediction. A coupled meteorological-photochemical model integrates these complex processes in time to generate predictions of the distributions and concentrations of chemical species, in addition to the wind, pressure, temperature, and other meteorological fields.

Two modes, research and operational, can be distinguished for such numerical models. In research mode, model results are not required to be available in real time, and these runs can be made over large simulation domains with close spacing of the computational nodes or grid points (i.e., at fine resolution) and with sophisticated representation of physical processes. Model parameters can be adjusted for each run or series of runs if desired. In operational mode, however, model output is needed quickly for the current forecast cycle, requiring significantly greater computational efficiency through coarser resolution and simpler physical representations; also, model constants and other parameters must be fixed a priori.

Air-quality forecasting is a significant challenge. Field studies such as the one presented here are interesting, but they are costly. So an important question is, How do such field experiments contribute to the overall goal of being able to provide accurate air-quality predictions? Measurement campaigns provide three kinds of information. First, they document important features and their evolution, features such as sea-breeze convergence zones, blobs of ozone and other pollutants, inversions, etc. Second, they provide data fields that can be used to directly calculate error statistics for quantitative verification of model capabilities. Third, field measurements can provide insight into what key meteorological and chemical processes produce these features. Such processes could include surface heating, boundary layer growth, turbulent mixing, decoupling of the flow in the upper daytime mixed layer from the surface at night, atmospheric radiation, and many others. This information addresses understanding of meteorology and chemistry, and an important subset of field projects directly targets understanding of specific processes, so they can be better represented in models. When features appear to be well represented in models, this understanding allows researchers to assess whether the models are "getting the right answer for the right reason." This can be important for ascertaining whether the models can discriminate between two cases that are superficially similar, but where one develops high-ozone pollution and the other does not.

Once these features and processes have been identified, the next important question is, Is a currentgeneration numerical model capable of faithfully representing them? It is a role of research-grade NWP models to answer this question. If the answer is yes, that state-of-the-art numerical models are able to properly represent the important features and processes, then the role of research-grade models, in concert with the measurement results, is to specify what is necessary for operational models to provide accurate forecasts - what physics and chemistry needs to be in the models, what resolution is necessary, and what boundary and initial conditions are needed, etc. However, if the answer is no, that current-generation models cannot properly represent the important processes, or cannot simulate the evolution of important features, then the role of the research models and the observational results becomes to specify the uncertainty in the model predictions, and how that translates into uncertainty in forecasts. The uncertainty can be uncertainty in concentrations of pollutants, timing of events, or locations of regions of high or low concentrations, for example.

Previous studies have demonstrated the significant advantages of simultaneously measuring both the detailed wind field and the distribution of a tracer material (Banta et al. 1996, 2004). Here we note that careful air-chemistry measurements, as were available during TexAQS2000, represent excellent "tracers of opportunity" to go with detailed winds available from profiler arrays, Doppler lidars, and surface networks. Often air-chemistry measurements can contribute to unambiguous identification of where the air parcel "tracer" came from, and they can also provide valuable information on times of transit, by evaluating how far chemical reactions have proceeded (i.e., the chemical age of the air parcels). Such combined information can be invaluable for the validation of many different kinds of models.

The role of the operational numerical model is to provide guidance to forecast providers and decision makers. In conditions where model assessments have indicated high confidence in the model predictions, the model output may be directly usable as a quantitative forecast. On the other hand, under meteorological conditions where greater uncertainty has been demonstrated by comparisons with observations, the implications of the model output to air quality will need to be interpreted by a forecaster or other specialist. 
Second, under suitable wind conditions, the sea breeze can assume a frontal structure (Simpson 1994) along the coastline of Galveston Bay and the Gulf of Mexico and advance inland (Figs. 1b, 2). Numerical studies and observations of the sensitivity of sea-breeze development to ambient flow (e.g., Estoque 1962; Banta et al. 1993) indicate that the sea-breeze front is sharper, slower, and

a)

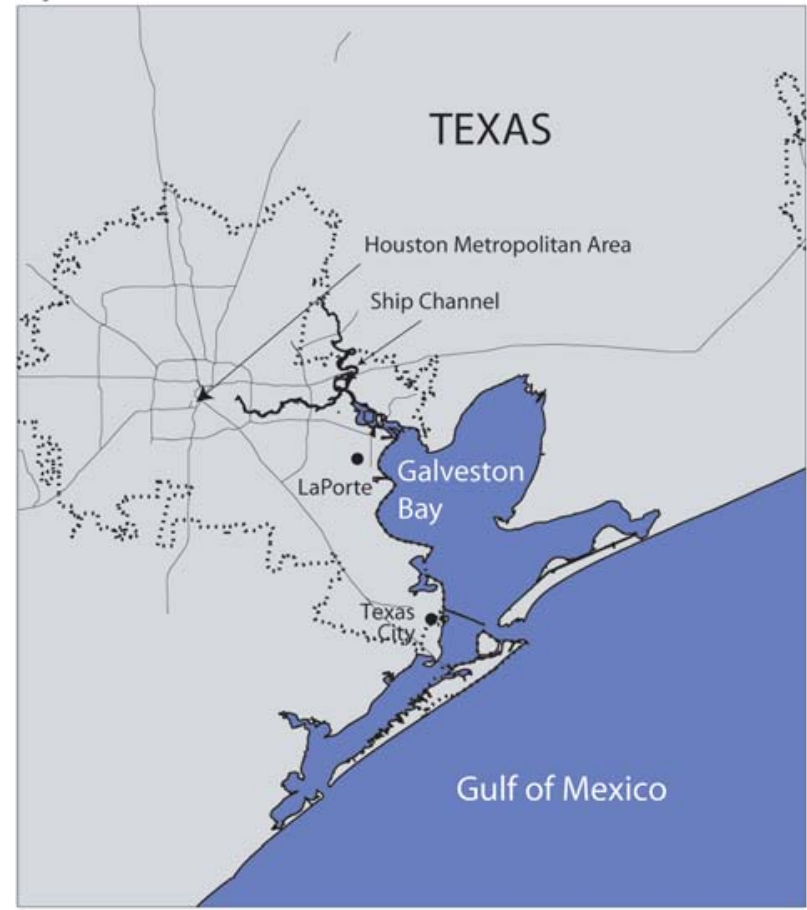

b)

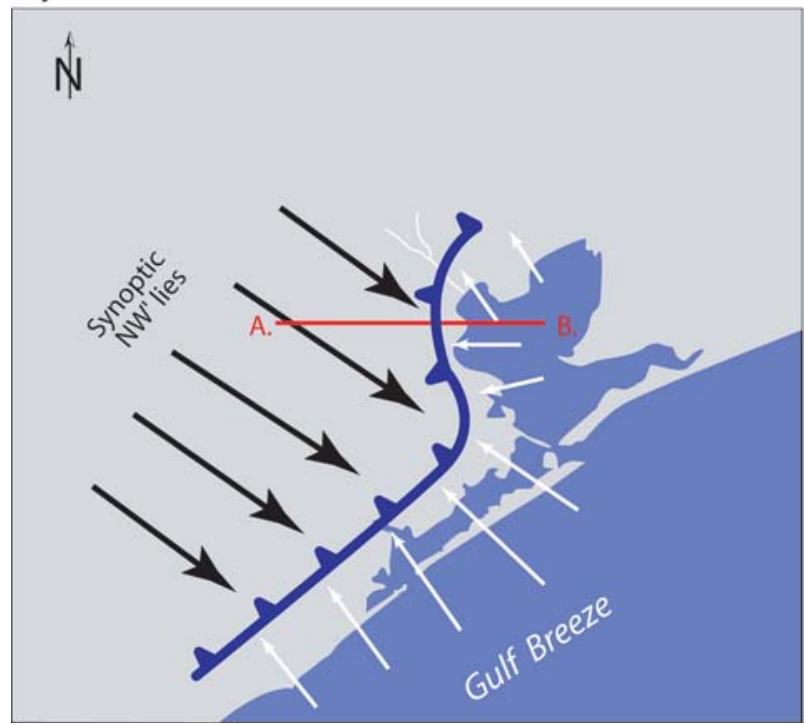

FIG. I. Maps of Houston-Galveston Bay region (a) showing urban-industrial area enclosed in the dotted line and (b) depicting the incipient sea breeze stalled along the shore of Galveston Bay, as occurred in late afternoon on 30 Aug 2000. Line AB shows the location of vertical cross section depicted in Fig. 8 . arrives later in the day in offshore flow than in calm or onshore flow. During TexAQS2000, many days had light or onshore large-scale flow, and the sea-breeze front generated by the coastal temperature contrast moved inland by late morning or midday. On several days of the pollution episode described here, however, the large-scale flow was offshore, and the sea-breeze front did not move inland

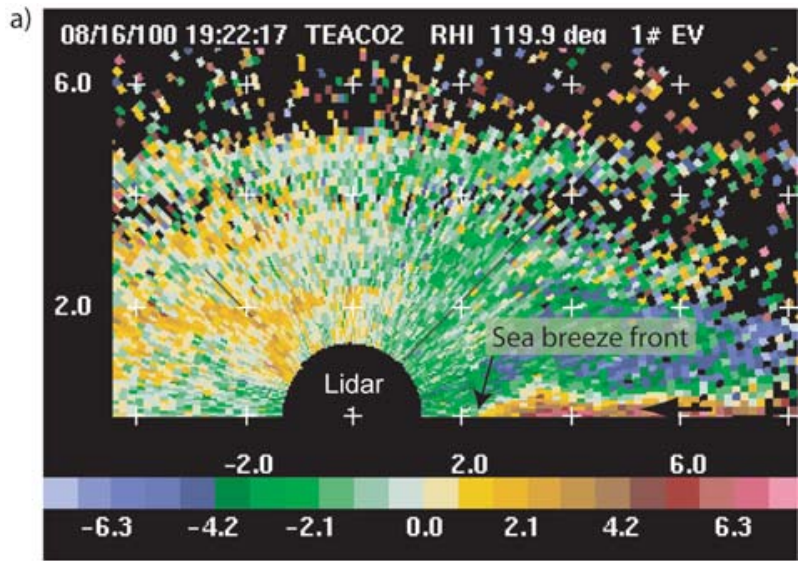

b)

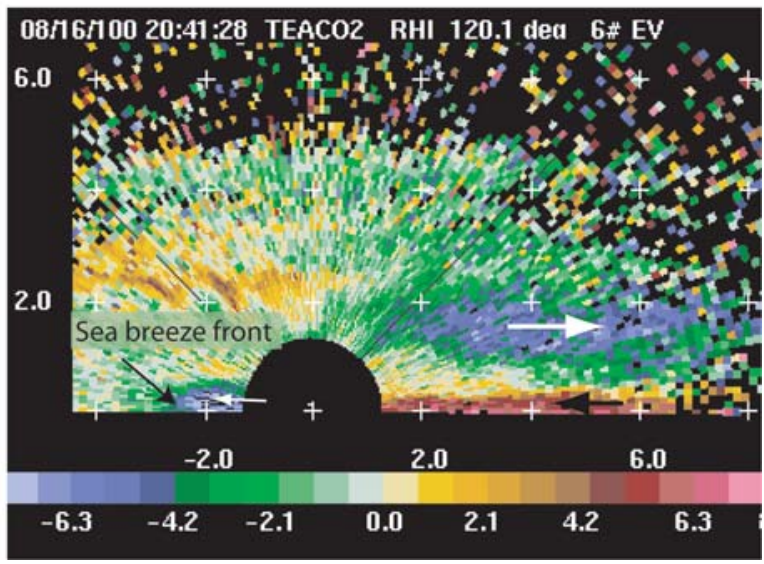

FIG. 2. Example of the advance inland of the bay-breeze front on 16 Aug 2000 as depicted in vertical crosssectional scans perpendicular to the coast by a Doppler lidar sited at LaPorte. Cross sections are of Doppler radial velocity (color bar in $\mathrm{m} \mathrm{s}^{-1}$ ) with positive values indicating flow toward the lidar. Horizontal axis is distance in $\mathrm{km}$ from the lidar with positive values pointing toward $120^{\circ}$ azimuth, and vertical axis is height in $\mathbf{k m}$. White crosses are tick marks at $2-\mathbf{k m}$ intervals, and lidar is located at $(0,0)$. (a) 1322 and (b) I44I CST. The bay-breeze front exhibits typical density current structure as has often been observed in sea-breeze flows (Simpson 1994). The leading edge advanced from $x=2.2$ to $-2.9 \mathrm{~km}$ over the 79-min period depicted, for a speed of $1.1 \mathrm{~m} \mathrm{~s}^{-1}$. The Doppler lidar is a scanning, remote sensing system similar to a Doppler radar, except the transmitted wavelength is much shorter. The scattering targets are aerosol particles instead of hydrometeors; thus the lidar is capable of obtaining data in clear air. 
until mid- to late afternoon, initially moving slowly into the opposing flow. Thus, at first the sea breeze stalled just inland. At larger scales, stalled synoptic stationary fronts have also been associated with highpollution events (McNider et al. 1995).

Thus, both forms of the sea breeze near Houston-frontal structure and the superposition of the larger-scale flow with the inertia-gravity wind oscillation-would produce a band of light winds just inland from the shore in the vicinity of the sources for an hour or so in mid- to late afternoon. These conditions favor the buildup of high pollutant concentrations.

CASE STUDY OF 30 AUGUST 2000. An especially dramatic example of these processes occurred on 30 August 2000. The bay and gulf breezes did not advance inland along the western shore of Galveston Bay until midafternoon as just described. The 30th of August was part of a nine-day pollution episode and heat wave, during which the maximum surface temperature exceeded $40^{\circ} \mathrm{C}$ on several of the days, and an all-time high temperature of $109^{\circ} \mathrm{F}\left(43^{\circ} \mathrm{C}\right)$ was recorded on 4 September. As a rule, high temperatures accelerate chemical reactions and thus are another condition favorable to rapid production of high concentrations of secondary pollutants, such as ozone. On 30 August the highest mean 1-h concentration of $\mathrm{O}_{3}$ for the Texas 2000 campaign was measured in the Houston surfacemeasurement network (199 ppb) at LaPorte (Fig. 3a).

Daytime sea-breeze effects. The evolution of the sea breeze and its effect on $\mathrm{O}_{3}$ concentrations, as seen by the kind of data that are routinely available for operational forecasting and modeling in the Houston area, are shown in Fig. 4. The data are from a mesonet of meteorological and chemistry measurements at the surface. Little or no measured data are routinely available above the surface. The TexAQS2000 field project thus provides an opportunity to demonstrate and assess the value added of measurements aloft, as well as more detailed chemistry data and more extensive meteorological networks.
The surface mesonet data show three distinct periods: 1) A period of offshore flow near the surface, symptomatic of the large-scale flow, persisted for most of the morning and early-afternoon hours in the Houston-Galveston area. At 1100 central standard time (CST; Fig. 4a) the northwesterly flow and relatively low $\mathrm{O}_{3}$ concentrations were representative of conditions that prevailed through noon on this day. After noon the winds became lighter inland and along the shore of the bay, and $\mathrm{O}_{3}$ concentrations began to increase over much of the urban area. 2) A period of weak winds along the shore of Galveston Bay indicated the initial influence of the sea breeze (bay breeze). By 1500 CST (Fig. 4b) a weak bay breeze had begun at LaPorte, with calm to light-and-variable winds just inland. Ozone concentrations climbed to their highest values, especially in the LaPorte-Ship Channel vicinity (the bold, solid line represents the Ship Channel). 3) A period of stronger southerly flow indicated the gulf breeze in the late afternoon. By 1700 CST (Fig. 4c) the direction of the sea breeze rotated to a southerly direction. The early evening winds at 1900 CST (Fig. 4d) showed even stronger southerly flow, which carried the high- $\mathrm{O}_{3}$ air northward out of the measurement network. The near-surface winds throughout the network continued to rotate to southwesterly and then

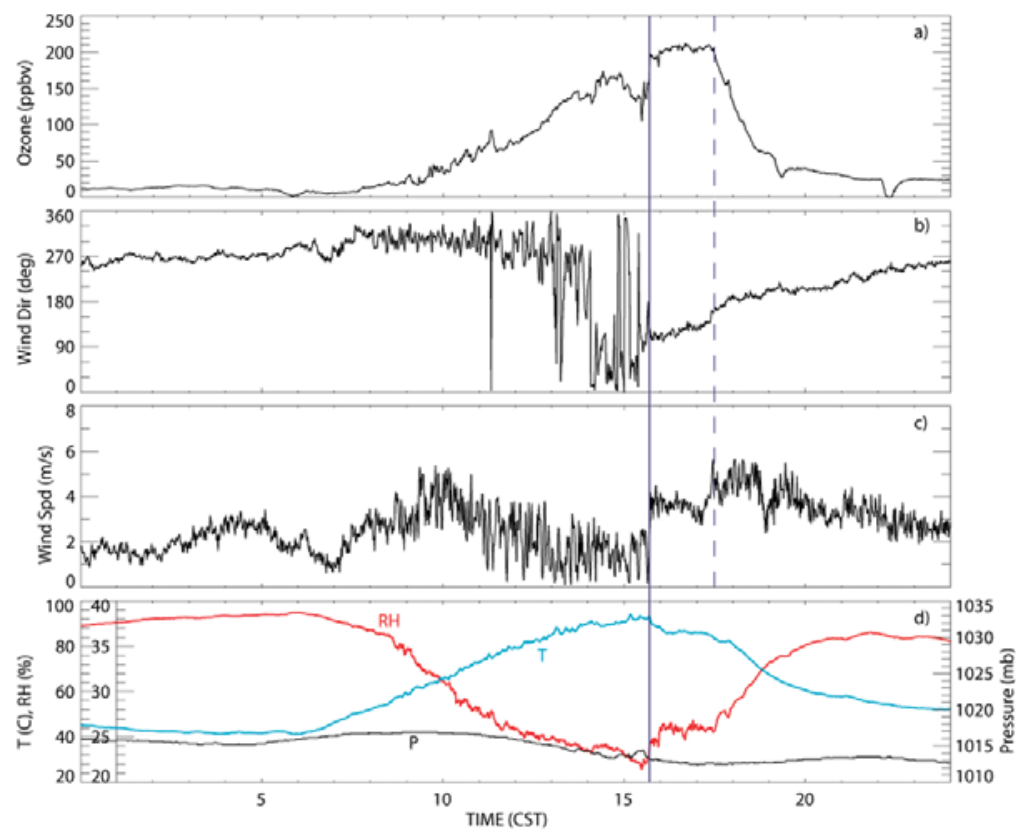

FIG. 3. Time series from measurements at the LaPorte ground site of (a) ozone concentration (ppb), (b) wind direction $\left({ }^{\circ}\right),(\mathrm{c})$ wind speed $\left(\mathrm{m} \mathrm{s}^{-1}\right)$, and (d) temperature $\left({ }^{\circ} \mathrm{C}\right.$, blue line), relative humidity (\%, red line), and pressure ( $\mathrm{mb}$, black line). Northwesterly offshore flow is evident prior to 1400 CST. The bay-breeze frontal passage (solid vertical line) shows up as upward jumps in humidity, ozone, and wind speed between 1500 and 1600 CST, a dip in temperature, and a change in behavior of the winds from light and variable to steady southeasterly flow. Dashed line indicates gulf breeze wind shift just before 1800 CST. 
Fig. 4. Maps of the Houston-Galveston Bay area showing changes in surface mesonet values of wind and ozone concentrations during the day of 30 Aug, indicative of information currently available operationally. Full wind barbs represent $5 \mathrm{~m} \mathrm{~s}^{-1}$ wind speeds, and half barbs, $2.5 \mathrm{~m} \mathrm{~s}^{-1}$. Color of station circles indicates ozone concentration (ppb, color bar at bottom), and the stations at LaPorte ("L") and Texas City ("T") are indicated. (a) At 1100 CST the northwesterly flow and relatively low $\mathrm{O}_{3}$ concentrations were representative of conditions that prevailed prior to noon during period I. (b) By I500 CST a weak bay breeze at LaPorte, with calm to light-and-variable winds just inland, were characteristic of period 2. (c) By 1700 CST the direction of the sea breeze rotated to a southerly direction, indicating the beginning of the gulf breeze and period 3. (d) The early evening winds at 1900 CST showed stronger southerly flow, which eventually rotated to southwesterly and then westerly directions through the evening.
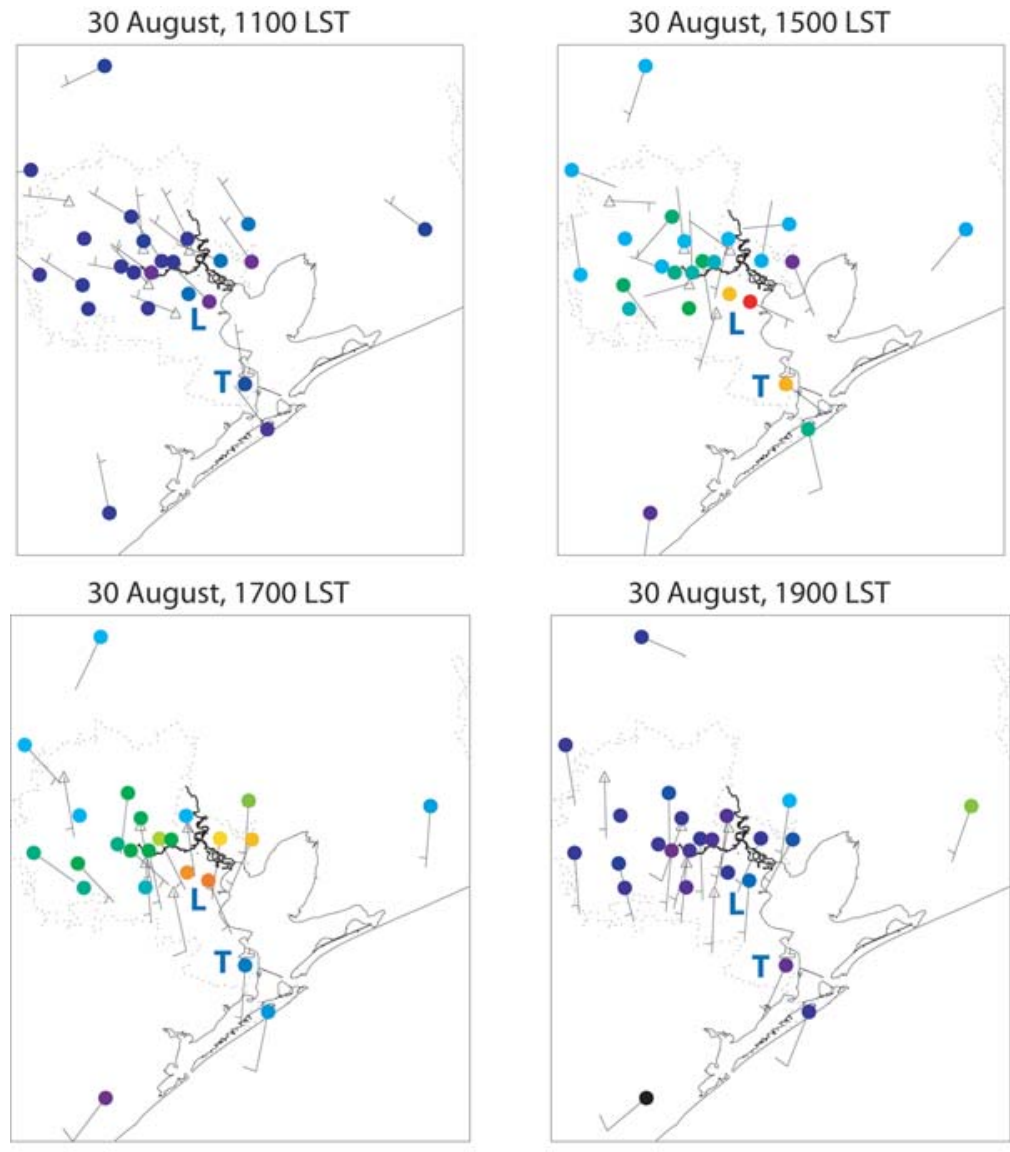

30 August, 1900 LST

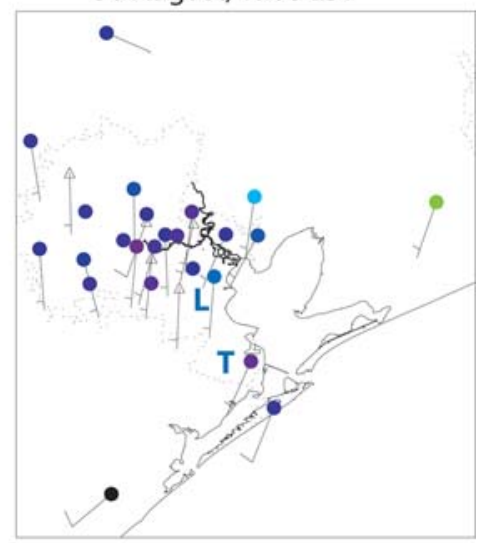

Ozone (ppbv)

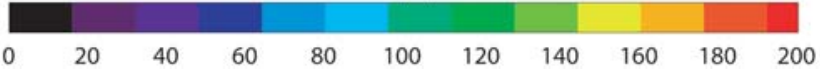

\section{SEA BREEZZE NEAR $30^{\circ}$ LATITUDE}

The sea breeze is a response to the forcing from a diurnally varying coastal heating gradient, which produces warmer temperatures over land than over water during the day, and cooler land temperatures at night. The lowlevel wind vector rotates through a clockwise (Northern Hemisphere) cycle under the influence of the Coriolis force. According to solutions to the appropriately scaled and linearized equations of motion (Rotunno 1983; Yan and Anthes 1987), the magnitude and nature of this response is highly sensitive to latitude.

The frequency of an oscillation is the reciprocal of its period. The diurnal period is the period of the earth's solar heating and cooling cycle $(24 \mathrm{~h})$. The inertial period is the half pendulum day $P$, where $P=2 \pi|f|^{-1}$, the Coriolis parameter $f=2 \omega \sin \varphi, \omega$ is the earth's rotation rate, and $\varphi$ is the latitude (Holton 1992). The two periods are equal at $30^{\circ}$, and the linear response dramatically changes character at this latitude. Poleward of $30^{\circ}$, the seabreeze response decays with distance from the coastline. Equatorward of $30^{\circ}$, the diurnal heating cycle triggers inertia-gravity waves that propagate horizontally and vertically away from the coastline. Near $30^{\circ}$, the heating period is nearly in resonance with the inertial period, and linear theory predicts a particularly strong and horizontally extensive response.

The latitude of Houston is just equatorward of $30^{\circ}$, the latitude where the two periods (or frequencies) are equal and the sea-breeze cycle is at maximum amplitude. This implies a particularly strong role for the seabreeze cycle in airflow and atmospheric transport in the Houston area, during periods when the large-scale flow is not too strong.

When the large-scale gradient wind is similar in magnitude to the sea-breeze cycle, the resultant wind will be twice as strong as either at one particular time of day, but it will be near zero $12 \mathrm{~h}$ later when the two winds cancel. During the warm season in Houston in 1998-2003, large-scale winds were light enough to permit this cancellation on about $20 \%$ of all days and over $50 \%$ of high-ozone days. Similarly, the cluster analysis of TexAQS days from August to September of 2000 indicated seabreeze and reversal patterns on $25 \%$ of all days, and on $45 \%$ of days with peak $\mathrm{O}_{3}$ concentrations $>120 \mathrm{ppb}$ (Darby 2005, manuscript submitted to J. Appl. Meteor.). 
westerly by midnight, following the wind-direction behavior at LaPorte shown in Fig. $3 \mathrm{~b}$ and the behavior predicted by inertia-gravity wave theory (Rotunno 1983). We note that a recent study using cluster analysis to categorize the TexAQS2000 surface-wind dataset also has shown that a three-phase reversal pattern, consisting of offshore flow, followed by at least an hour of stagnant conditions, followed by a sea breeze, typified the high- $\mathrm{O}_{3}$ days of the project (Darby 2005, manuscript submitted to J. Appl. Meteor., hereafter DAR), in agreement with an earlier study (Systems Applications International et al. 1995).

Vertical profiles of the horizontal winds, determined from conical scans of a Doppler lidar sited at LaPorte (Fig. 5), show that these wind patterns occupied a deeper layer of the boundary layer. The offshore flow prior to 1400 CST and the transition to light winds at $1400 \mathrm{CST}$ occurred through a layer more than $400 \mathrm{~m}$ deep. The sea breeze just before 1500 CST, on the other hand, began in a layer less than $100 \mathrm{~m}$ deep, growing deeper after 1530 CST.

During period 1 the northwesterly (offshore) flow earlier in the day resulted in low-pollution concentrations over land. Pollution from the Houston urban and Ship Channel areas was carried offshore to the southeast over Galveston Bay, as shown by airborne $\mathrm{O}_{3}$ lidar flight legs with the DC-3 over the bay and the Gulf prior to 1500 CST (Fig. 6a). These DIAL cross sections found high concentrations (up to $180 \mathrm{ppb}$ ) of $\mathrm{O}_{3}$ over Galveston Bay and the Gulf of Mexico, but not inland. Over the water the $\mathrm{O}_{3}$ pollution was confined in the vertical to a shallow layer only $500 \mathrm{~m}$ deep (Fig. 6b), because of the static stability of the air in contact with the cooler water surface of the bay, because of the mixing depth over land when the precursors were emitted, and because of sinking air motions over the bay. These sinking motions, or subsidence (which often appear in satellite images as an absence of cloudiness over Galveston Bay and which were also captured in high-resolution NWP models) are a compensatory current for rising motions along the sea-breeze front inland of the coast.

Airborne air-chemistry measurements (Ryerson et al. 2003) throughout this day and other days with similar meteorology showed high concentrations of ethylene, propylene, and nitrogen oxides $\left(\mathrm{NO}_{\mathrm{x}}\right)$, indicating that the source of the pollution in the ozone-rich air was primarily industrial-the facilities along the Ship Channel and the western shore of Galveston Bay.

Period 2 began when the sea breeze was first detected onshore at approximately 1500 CST (Fig. 3), and the sea-breeze front only penetrated a few kilometers inland by late afternoon (as depicted in Fig. 1b; cf. Figs. $4 \mathrm{~b}$ and 5). During this period, the DC-3 flew several parallel east-west flight legs across the shore from south to north (Fig. 7a), thus painting a $3 \mathrm{D}$ picture of the ozone distribution (Fig. 7b). The pollution formed a spectacular wall of ozone reaching more than $1 \frac{1 / 2}{\mathrm{~km}}$ high, with very high concentrations of $200 \mathrm{ppb}$ occupying much of this volume (Fig. 7b; Banta et al. 2002b). The focusing of pollution along this north-south band was a result of a region of strong convergence just inland and parallel to the western shore of Galveston Bay, produced by the onshore sea-breeze flow behind the front encountering the offshore flow, as depicted in Fig. $1 b$. We note that the offshore flow inland ahead of the sea-breeze front had the effect of bringing urban pollutants into the convergence zone, where they could mix with the industrial emissions there, potentially influencing the formation of secondary pollutants. 
a)
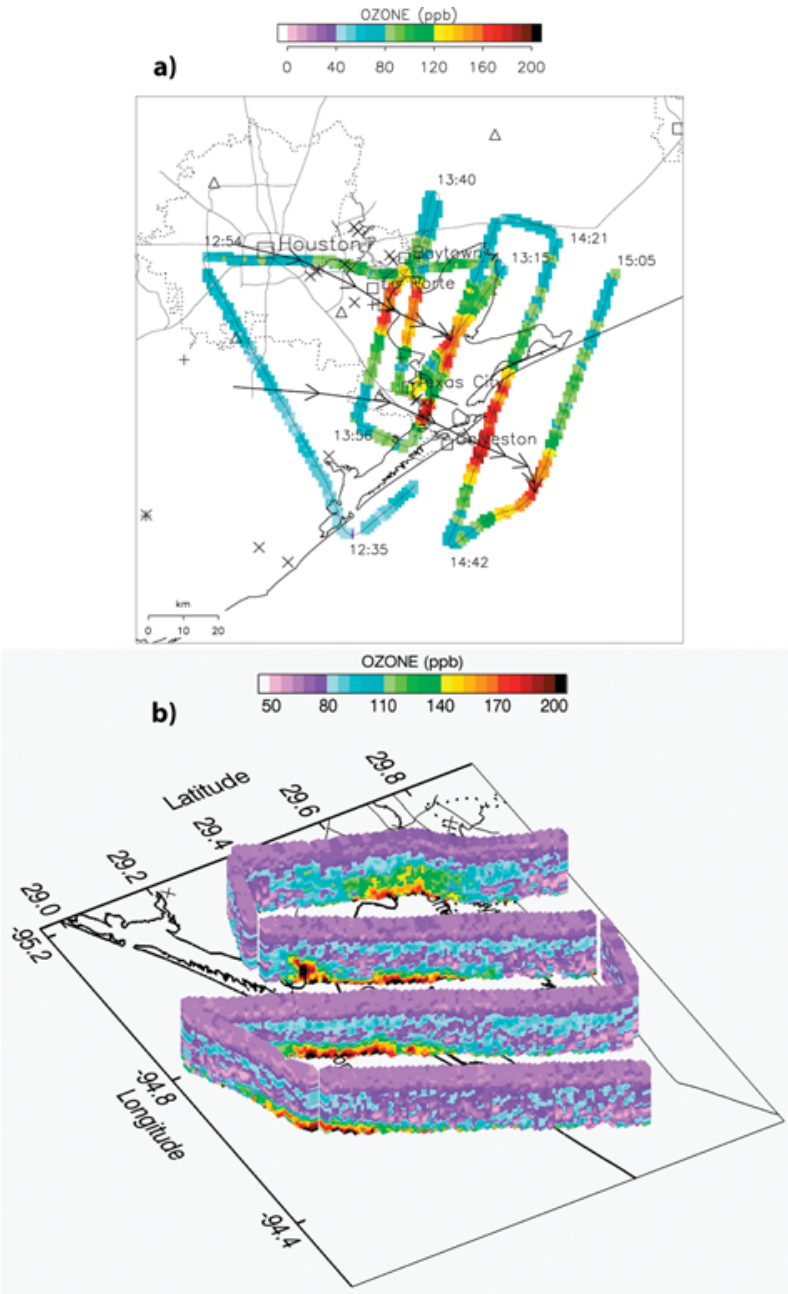

Fig. 6. (a) Early afternoon flight track of the ozoneprofiling DC-3 aircraft superimposed over a map of the Houston-Galveston Bay area, showing high- $\mathrm{O}_{3}$ concentrations over Galveston Bay and the Gulf of Mexico. Color coding indicates the $\mathrm{O}_{3}$ concentration (ppb) averaged between 200 and $500 \mathrm{~m}$ MSL. Black arrows trace 8-h back trajectories originating from the location of maximum ozone of the flight legs indicated. Each arrow segment of the trajectories represents I $h$ of transport according to interpolation of the radar wind-profiler data. Trajectories show that the air in the pollution maxima passed over sources in the Houston urban area and near Texas City. Symbols are as follows: $\square$ city, $\diamond$ airport, + power plant, $\triangle$ profiler site, and $x$ chemical plant. Times indicated on the flight tracks are in CST. (b) Three-dimensional distribution of ozone from vertical cross sections (color bar at top in $\mathrm{ppb}$ ) for the flight legs indicated in (a), superimposed on map of the Houston-Galveston Bay area. The height of the measurements extends from the surface to $2000 \mathrm{~m}$. Vertical cross sections of $\mathrm{O}_{3}$ concentrations show that the high- $\mathrm{O}_{3}$ values over water were confined to a shallow layer less than $\mathbf{5 0 0} \mathrm{m}$ deep. a)
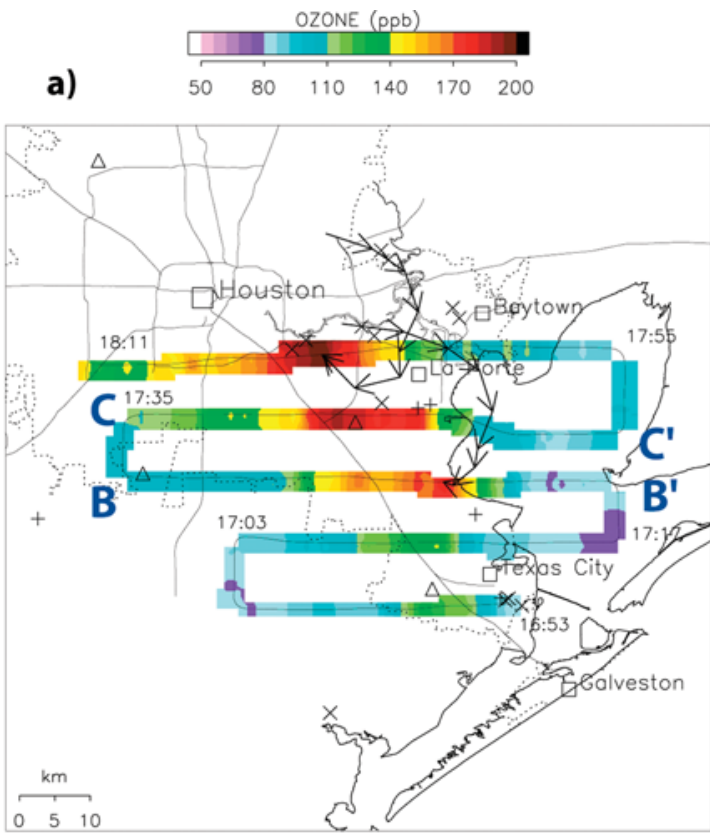

b)

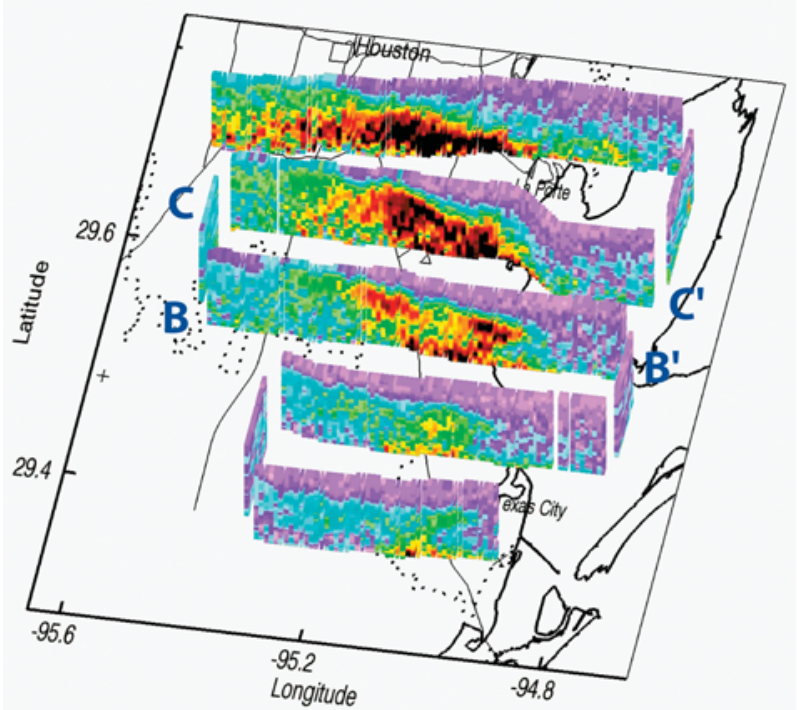

Fig. 7. (a) Late-afternoon flight track showing north-south band of high ozone, $20 \mathrm{~km}$ inland from the western shore of Galveston Bay. As in Fig. 6a, color coding indicates the mean ozone concentration (ppb) between 300 and $1600 \mathrm{~m}$ MSL, and black arrows indicate 8-h back trajectories interpolated from radar wind-profiler data. Times indicated on the flight tracks are in CST. (b) Three-dimensional distribution of ozone from vertical cross sections (color bar at top in ppb) for the flight legs indicated on Fig. 7a, superimposed on map of the Houston-Galveston Bay area. Height of the measurements extends from 300 to $2000 \mathrm{~m}$. High- $\mathrm{O}_{3}$ concentrations of nearly $200 \mathrm{ppb}$ penetrate to heights approaching $2 \mathrm{~km}$ MSL. Late-afternoon recurving trajectories in (a) show that the air in the high-pollution band along the coast passed over the Ship Channel area. Symbols are as in Fig. 6. 
Besides the buildup of emissions, this flow pattern also produced another effect favorable to creating high-pollution concentrations: onshore flow brought the shallow layer of pollution released earlier in the day, which had drifted out over the bay, back over many of the sources for a second dose. Aged air with high $\mathrm{O}_{3}$ thus received fresh input of precursor compounds, which then produced even more $\mathrm{O}_{3}$ in the pollutant wall. Although this has been hypothesized to happen, this is the first documentation of the extent and vertical structure of the pollution. A summary of the events leading to the high-pollution concentrations on this day is illustrated in Fig. 8.

Low-level convergence lines, such as the sea-breeze front, are regions of ascending air. In addition to revealing how widespread the pollution distribution became, the airborne ozone-DIAL measurements also revealed how strong and deep the convergence and updraft zone was over the linear north-south sea-breeze front along the west shore of the bay. As shown in Fig. 7b, updrafts in the sea-breeze convergence zone were very effective in lofting these large pollution concentrations high into the atmospheric boundary layer.

The shift to stronger southerly component flow to begin period 3 at La Porte just before 1800 CST (Fig. 3 , dashed vertical line) was also the beginning of the decline in $\mathrm{O}_{3}$ concentrations. The stronger near-surface flow was effective in carrying the high-pollution concentrations to the north and out of the surface measurement network (Fig. 4d).

Nocturnal transport and regional background pollution. The lofting of large concentrations of pollutants to high altitudes in the boundary layer also influences air quality on larger, more regional scales. The deep penetration of pollutants means that high concentrations were available for transport by the winds aloft. The late-afternoon winds in the middle and upper boundary layer were weak, so the pollutants did not drift far from the sources until after sunset. But because the deep wall of pollution formed late in the day, it was available for transport by accelerated nocturnal winds.

Overnight trajectories constructed from radar wind-profiler and rawinsonde data (Fig. 9) show three transport layers: pollution in the lower layer (red, black trajectories) was carried by a southwesterly low-level jet (LLJ) toward Beaumont, Texas, and Louisiana; pollution in a second layer of stagnant flow (green) remained over the Houston area; and pollution in an upper, easterly flow layer (blue) was carried to the west toward Austin and San Antonio. The following day this pollution would mix down to the surface at its location. That portion of the pollution that stayed in place in the stagnant layers over Houston (green trajectory) would augment that (following) day's pollution over the urban area. The other portions that were carried away from the urban-industrial centers (red, black, blue trajectories) 
would mix out and become part of the buildup of rural background, in much the same manner as we found in the region around Nashville, Tennessee (Banta et al. 1998).

The effectiveness of such overnight transport processes from cities, power plants, and other source regions in enhancing rural pollution levels is illustrated by an analysis of airborne $\mathrm{O}_{3}$ profile data for rural areas outside of the Houston urban and Ship Channel plumes (Fig. 10). This analysis shows an increase in background $\mathrm{O}_{3}$ concentrations from $\sim 60$ to $80 \mathrm{ppb}$ from 29 August to 1 September during the pollution episode. The buildup of rural $\mathrm{O}_{3}$ is an important aspect of air pollution episodes for two reasons. First, persistent $\mathrm{O}_{3}$ concentrations of 80 $\mathrm{ppb}$ or more can be harmful to vegetation (forests, crops), livestock, and human health. Second, the incremental increase in $\mathrm{O}_{3}$ added by an urban area each day augments an ever-increasing background value, resulting in increased peak values in the city as the episode proceeds.

DISCUSSION. The unique picture provided by vertical cross sections from the airborne $\mathrm{O}_{3}$ DIAL in conjunction with the other instrumentation deployed during TexAQS2000 has allowed researchers

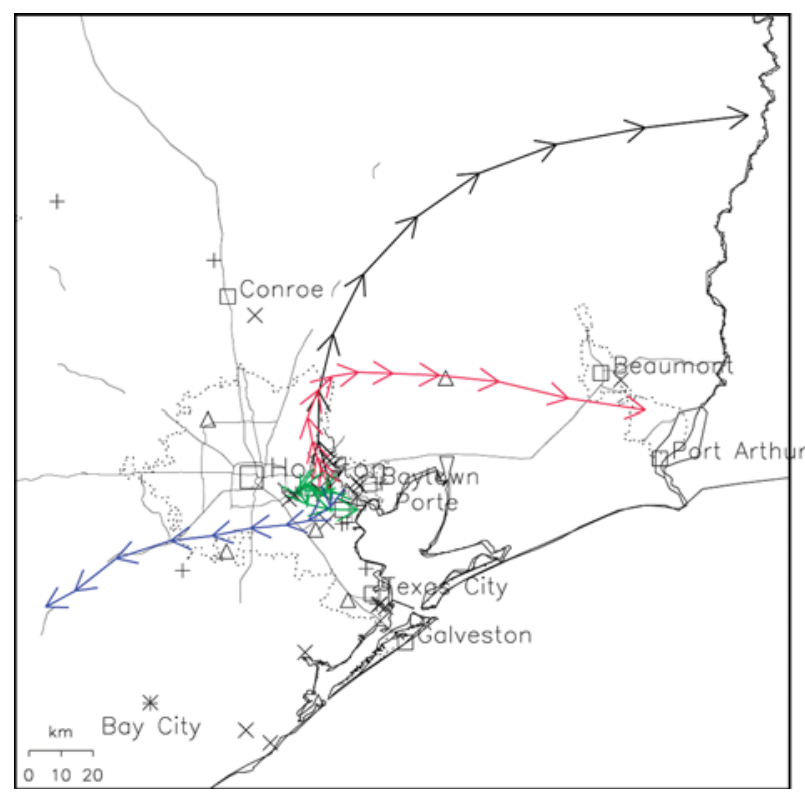

FIg. 9. Twelve-hour forward trajectories showing overnight transport, calculated from hourly radar wind-profiler data starting at 1800 CST and ending at 0600 CST. Winds were averaged over four $300-\mathrm{m}$-deep layers below $1400 \mathrm{~m}$, where red is for the $200-500-\mathrm{m}$ MSL layer, black is the 500-800-m layer, green is the $800-1100-\mathrm{m}$ layer, and blue is the I100-1400-m layer. to observe for the first time the extent and depth of $\mathrm{O}_{3}$ pollution produced in the Houston area; to assess the role of meteorological processes in producing that pollutant distribution; and to appreciate some of the consequences of that distribution, such as the implications of the deep $\mathrm{O}_{3}$ penetration to regional transport and to the buildup of rural background concentrations of pollutants.

Detailed analyses of this kind are important for documenting which meteorological ingredients are

a)

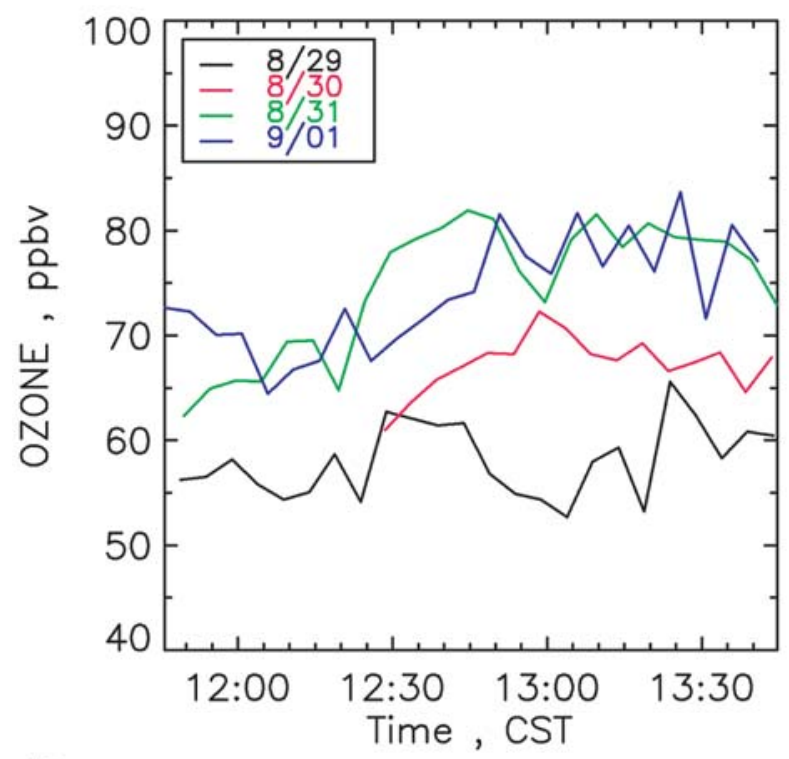

b)

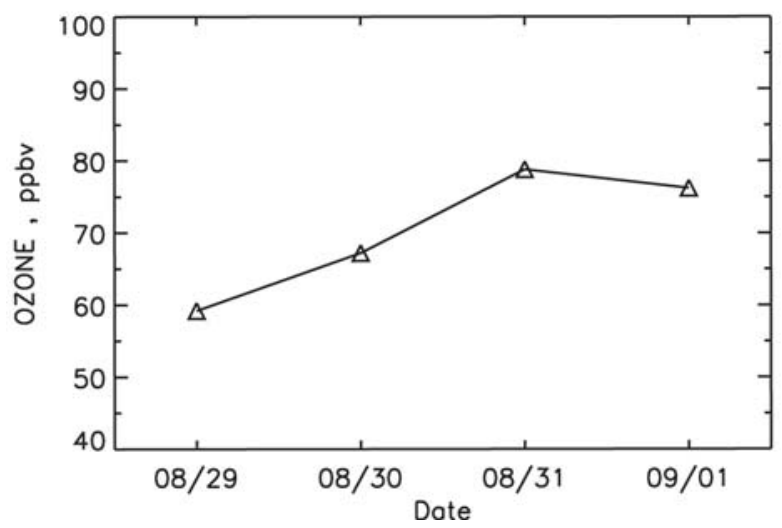

FIG. 10. (a) Time series of rural background ozone concentrations at midday for four days of the pollution episode. Concentrations increased by 20 ppb from 29 Aug to $3 \mathrm{I}$ Aug and I Sep. Values were obtained from airborne $\mathrm{O}_{3}$ lidar measurements by averaging data at $1500 \mathrm{~m}$ MSL over all flight-leg segments that were outside of significant source activity; i.e., the current day's plumes from urban areas, power plants, industrial sources, etc., were excluded from this "rural" sampling. (b) Data for each day in (a), averaged over the period from 1230 to $1330 \mathrm{CST}$. 
needed to accurately predict high-pollution events. In this case, the important processes or ingredients can be summarized as follows:

- The timing and location of the sea-breeze front or convergence zone are key, because it was necessary for this zone to stall over the sources for more than an hour or so, to allow the emissions to concentrate at times when photochemistry was active. This happened when the sea breeze formed late in the day in offshore large-scale flow, not only in the case presented here, but also on several other high-pollution days (e.g., 21, 29, and 31 August).

- For the very highest pollutant levels, the largescale flow should produce low-level winds ahead of the sea-breeze front that are nearly opposite in direction to the sea breeze when it forms (see also DAR), so that the pollutants that have been carried offshore in the morning can be brought back over the sources for the extra dose of pollutants, as occurred in the case study presented here. The direction of this inland flow is also likely to be important for bringing the Houston urban emissions into the convergence zone, where they can mix with the industrial emissions there, potentially further augmenting the production of secondary pollutants.

- High temperatures accelerate chemical reactions.

- The height to which pollutants mix is another important quantity, because it determines the vertical dimension of dilution. For example, on 31 August, the day after the present case study, the sea breeze developed in a similar manner to the present case, but the $\mathrm{O}_{3}$ wall reached a height of 2.8 instead of $1.8 \mathrm{~km}$. Peak 1-h $\mathrm{O}_{3}$ concentrations at the surface reached "only" $168 \mathrm{ppb}$ as a result of this increased dilution in the vertical and a slightly different large-scale flow direction.

- The nocturnal acceleration of flow above the surface into low-level jets and other nocturnal flows must be accurately predicted, to faithfully portray the nocturnal transport and dispersion of this deep layer of pollutants and its effect on the next days' pollution, as well as the buildup of rural pollutants on subsequent days and throughout a pollution episode.

A critical "wild card" in these processes, of course, is the role of inadvertent, accidental, or unanticipated releases or spills (referred to as "upsets" in the Houston area), or that of unreported emissions of reactive compounds. These events would make it difficult to interpret measured concentra- tions and can produce significant errors in forecast pollutant concentrations. Such events do occur, and it will be important to somehow account for them in any forecast scheme.

Important tools for interpreting all of these processes into a quantitative prediction are NWP models (Seaman 2000; Dabberdt et al. 2004). A critical question is, How well do such models represent these key meteorological processes? The sea breeze was one of the first mesoscale phenomena to be simulated numerically, and experience with such simulations has extended over many decades. Nevertheless, it is still difficult for current NWP models, even in research mode, to reproduce the location, timing, depth, and intensity of the sea-breeze front, and the accompanying stagnation and recirculation of local daytime winds, to sufficient accuracy for reliable quantitative predictions of the highest pollution concentrations. Similarly, predictions of mixing depth and the direction and speed of the nocturnal LLJ do not routinely provide the fidelity needed for accurate pollutionconcentration forecasts. Operational models, of course, would be even less able to provide accurate quantitative predictions.

For the present case, the importance of smallscale mesometeorological processes in both daily pollutant maxima and in the regional buildup was demonstrated. Here these processes resulted from the complex coastal landscape, but in other urban areas such processes could be a result of mountainous or other complex-terrain influences on low-level airflow. Necessary improvements to the numerical modeling systems will require a more accurate representation of many physical processes in the models, in addition to taking advantage of more powerful computers to improve model resolution (Seaman 2000; Dabberdt et al. 2004; Bao et al.2004). These processes include the representation of nocturnal mixing and LLJ evolution (Mahrt 1998; Banta et al. 2002a), atmospheric radiation (Zamora et al. 2003), cloud processes, the exchange of energy, momentum, and substances between the atmosphere and the earth's surface (Zhong and Fast 2003; Poulos and Burns 2003), as well as many other processes (Seaman 2000; Dabberdt et al. 2004). The testing and validation of these models will require comprehensive measurement campaigns in which both chemistry and meteorology are measured in detail.

Fortunately, more detailed datasets from such comprehensive field-measurement campaigns are becoming available. In addition to TexAQS2000, a major campaign at the New England coast took place in the summer of 2002, the New England Air Quality Study (NEAQS2002). A second, even more 
comprehensive New England campaign was just completed in the summer of 2004, and another Texas study is planned for summer 2006 in the Houston area, with an objective of further understanding rural background pollution levels. Each of these projects will emphasize closer coordination with NWP groups, including the WRF-Chem development team, university scientists, and the National Centers for Environmental Prediction (NCEP), the NOAA office responsible for providing the model air-quality predictions.

ACKNOWLEDGMENTS. This research was funded by the Southern Oxidants Study of the NOAA Health of the Atmosphere program, with additional funding from the Texas Commission on Environmental Quality (TCEQ; formerly the Texas Natural Resources Conservation Commission). Radar wind-profiler data used in the trajectory calculations were provided by the Regional Weather and Climate Applications Division of ETL, the NOAA/Aeronomy Laboratory, Argonne National Laboratory, Pacific Northwest National Laboratory, the University of Alabama, Huntsville, and the Texas Commission on Environmental Quality. The lead author would like to acknowledge the many enlightening discussions with his friend and colleague, Dr. Jian-Wen Bao, on the relative roles of measurements and numerical modeling, as discussed in the modeling sidebar. We thank Dr. Bao and Ms. Sara Michelson for helpful reviews of the manuscript, and Dr. Richard T. McNider for helpful discussions.

\section{REFERENCES}

Alvarez, R. J., II, C. J. Senff, R. M. Hardesty, D. D. Parrish, W. T. Luke, T. B. Watson, P. H. Daum, and N. Gillani, 1998: Comparisons of airborne lidar measurements of ozone with airborne in situ measurements during the 1995 Southern Oxidants Study. J. Geophys. Res., 103, 31 155-31 171.

Banta, R. M., L. D. Olivier, and D. H. Levinson, 1993: Evolution of the Monterey Bay sea breeze layer as observed by pulsed Doppler lidar. J. Atmos. Sci., 50, 3959-3982.

$\longrightarrow$, — P. H. Gudiksen, and R. Lange, 1996: Implications of small-scale flow features to modeling dispersion over complex terrain. J. Appl. Meteor., 35, 330-342.

— - and Coauthors, 1998: Daytime buildup and nighttime transport of urban ozone in the boundary layer during a stagnation episode. J. Geophys. Res., 103, 22 519-22 544.

— R. K. Newsom, J. K. Lundquist, Y. L. Pichugina, R. L. Coulter, and L. Mahrt, 2002a: Nocturnal low-level jet characteristics over Kansas during CASES-99. Bound.-Layer Meteor., 105, 221-252.

_ C. J. Senff, L. S. Darby, T. B. Ryerson, M. Trainer, and R. J. Alvarez II, 2002b: 3-D distribution of ozone during the major pollution event of 30 August 2000 during TexAQS2000. Preprints, Fourth Conf. on Atmospheric Chemistry: Urban, Regional, and Global Scale Impacts of Air Pollutants, Orlando FL, Amer. Meteor. Soc., 267-269.

— L. S. Darby, J. D. Fast, J. O. Pinto, C. D. Whiteman, W. J. Shaw, and B. D. Orr, 2004: Nocturnal low-level jet in a mountain basin complex. Part I: Evolution and implications to other flow features. J. Appl. Meteor., 43, 1348-1365.

Bao, J.-W., S. A. Michelson, S. A. McKeen, and G. A. Grell, 2004: Meteorological evaluation of a weatherchemistry forecasting model using observations from the Texas AQS 2000 field experiment. J. Geophys. Res., in press.

Bell, M. L., A. McDermott, S. L. Zeger, J. M. Samet, and F. Domenici, 2004: Ozone and short-term mortality in 95 US urban communities, 1978-2000. J. Amer. Med. Assoc., 292, 2372-2378.

Dabberdt, W. F., and Coauthors, 2004: Meteorological research needs for improved air quality forecasting. Bull. Amer. Meteor. Soc., 85, 563-586.

Estoque, M., 1962: The sea breeze as a function of the prevailing situation. J. Atmos. Sci., 19, 244-250.

Holton, J. R., 1992: An Introduction to Dynamic Meteorology. $3 \mathrm{~d}$ ed. Academic Press, 511 pp.

Kleinman, L. I., P. H. Daum, D. Imre, Y.-N. Lee, L. J. Nunnermacker, S. R. Springston, J. Weinstein-Lloyd, and J. Rudolph, 2002: Ozone production rate and hydrocarbon reactivity in 5 urban areas: A cause of high ozone concentrations in Houston. Geophys. Res. Lett., 29, 1467, 10.1029/2001GL014569.

Mahrt, L., 1998: Stratified atmospheric boundary layers and breakdown of models. J. Theor. Comput. Fluid Dyn., 11, 263-280.

McHenry, J., W. F. Ryan, N. L. Seaman, C. J. Coats, J. Pudykiewicz, S. Arunachalam, and J. M. Vukovich, 2004: A real-time Eulerian photochemical model forecast system. Bull. Amer. Meteor. Soc., 85, 525-548.

McNider, R. T., W. B. Norris, A. Song, S. F. Mueller, and R. Bornstein, 1998: The role of convergence zones in producing extreme concentration events. Preprints, 10th Joint Conf. on the Applications of Air Pollution Meteorology with the A\&WMA, Phoenix, AZ, AMS, 68-72.

National Academy of Sciences, 1991: Rethinking the Ozone Problem in Urban and Regional Air Pollution. National Academies Press, 524 pp. 
Poulos, G. S., and S. P. Burns, 2003: An evaluation of bulk Ri-based surface layer flux formulas for stable and very stable conditions with intermittent turbulence. J. Atmos. Sci., 60, 2523-2537.

Rotunno, R., 1983: On the linear theory of the land and sea breeze. J. Atmos. Sci., 40, 1999-2009.

Ryerson, T. B., and Coauthors, 2003: Effect of petrochemical industrial emissions of reactive alkenes and $\mathrm{NO}_{\mathrm{x}}$ on tropospheric ozone formation in Houston, Texas. J. Geophys. Res., 108, 4249, doi:10.1029/ 2002JD003070.

Seaman, N. L., 2000: Meteorological modeling for air-quality assessments. Atmos. Environ., 34, 2231-2259.

Senff, C. J., R. M. Hardesty, R. J. Alvarez, and S. D. Mayor, 1998: Airborne lidar characterization of power plant plumes during the 1995 Southern Oxidants Study. J. Geophys. Res., 103, 31 173-31 189.

Simpson, J. E., 1994: Sea Breeze and Local Wind. Cambridge University Press, 234 pp.

Systems Applications International, Sonoma Technology, Inc., Earth Tech., Alpine Geophysics, and A. T. Kearney, 1995: Gulf of Mexico air quality study, final report. Volume 1: Summary of data analysis and modeling. OCS Study MMS-95-0038, U.S. Dept. of the Interior, Minerals Management Service, Gulf of Mexico OCS Region, New Orleans, LA, 654 pp.

Vaughan, J., and Coauthors, 2004: A numerical daily air quality forecast system for the Pacific Northwest. Bull. Amer. Meteor. Soc., 85, 549-561.

Wert, B. P., and Coauthors, 2003: Signatures of terminal alkene oxidation in airborne formaldehyde measurements during TexAQS2000. J. Geophys. Res., 108, 4104, doi:10.1029/2002JD002502.

Yan, H., and R. A. Anthes, 1987: The effect of latitude on the sea breeze. Mon. Wea. Rev., 115, 939-956.

Zamora, R. J., and Coauthors, 2003: Comparing MM5 radiative fluxes with observations gathered during the 1995 and 1999 Nashville Southern Oxidants Study. J. Geophys. Res., 108, 4050, doi:10.1029/ 2002JD002122.

Zhong, S., and J. D. Fast, 2003: An evaluation of the MM5, RAMS, and Meso-Eta models at subkilometer resolution using field campaign data in the Salt Lake Valley. Mon. Wea. Rev., 131, 1301-1322. 